\title{
Nanotechnological approaches for the development of novel antimicrobial strategies
}

\section{Mohammed Dyia Hussien ${ }^{1}$, Luminiţa Măruţescu ${ }^{1,2}$,, Carmen Mariana Chifiriuc ${ }^{1,2}$}

\author{
${ }^{1}$ Department of Microbiology, Faculty of Biology, University of Bucharest, Aleea Portocalelor No. 1-3, 060101, \\ Bucharest, Romania; ${ }^{2}$ Research Institute of the University of Bucharest (ICUB), Spl. Independentei 91-95, \\ 76201, Bucharest, Romania
}

${ }^{\square}$ Correspondence to: Luminiţa Măruţescu, Department of Microbiology, Faculty of Biology, University of Bucharest, Aleea
Portocalelor No. 1-3, 060101, Bucharest, Romania E-mail: $\underline{\text { lumi.marutescu@ gmail.com }}$

Received: 6 January 2018 / Revised: 8 May 2018 / Accepted: 22 May 2018 / Available online: June 2018

\begin{abstract}
Due to their diverse and multiple antimicrobial features, inorganic and organic nanoparticles (NPs) represent promising candidates for the development of novel antimicrobial strategies, which could be used to complement current antimicrobial agents that fail to combat pathogens, including multidrug-resistant and biofilmforming microorganisms. The high surface / volume ratio of NPs provides a maximum loading of therapeutic molecules. Additionally, NPs coated with different antimicrobial agents could represent an important alternative strategy to combat biofilm infections. Among the most common types of NPs, the metal, metal oxide and carbonbased NPs are the most used for antimicrobial applications and the purpose of this review is to present some of their antimicrobial features.
\end{abstract}

Keywords: nanoparticles, antimicrobial, anti-biofilm

\section{Introduction}

Nanotechnology may be defined as the design, synthesis, and application of materials engineered at nanoscale size (Buzea et al., 2007). Nanoparticles (NPs) have been employed for the production of various nanoscale materials with multiple applications especially in disease diagnostics and therapeutics or both (theranostic platforms) (Bhatia 2016). NPs size is comparable with that of biomolecules and microbial cell structures, creating a platform allowing nanomaterial-bacteria interactions that could be fine-tuned through suitable surface modification (Jiang et al., 2015; Daniel and Astruc 2004). The high surface / volume ratio of NPs provides a maximum loading of therapeutic molecules, with multivalent interactions, that could effectively address antimicrobial resistance mechanisms, such as decreased permeability, (super)activation of multi-drug efflux pumps and antimicrobial degradation / modification (Miller et al., 2015; Gupta et al., 2016). Additionally, NPs coated with different antimicrobial agents could represent an important alternative strategy to combat biofilm infections. Among the most common types of NPs with size ranging from 1 to $100 \mathrm{~nm}$, the metal NPs (Ag), metal oxide NPs ( $\mathrm{ZnO})$ and carbonbased NPs (nanotubes) are the most used for antimicrobial purposes.
Structurally, NPs are consisting of two or three layers: a surface layer, an organic or inorganic shell material and the core material. Their surface may be functionalized with metal ions, small molecules, surfactants, polymers (Christian et al., 2008). Based on their size, NPs are classified into three categories: i) 1-D materials, consisting in a typically thin film or surface coating, deposited or grown by various methods; ii) 2-D materials, having two dimensions in the nanometer scale, e.g., asbestos fibers; iii) 3-D materials, deposited under conditions that create atomic-scale porosity, colloids, and free NPs with several morphologies, like quantum dots (Jores et al., 2004; Buzea et al., 2007). NPs could be fabricated by using top-down and bottom-up strategies. The top-down strategy involves the removing of crystal planes present on the substrate, so the building blocks are removed from the material to obtain the desired nanostructure. The bottom-up synthesis approach implies that the building blocks are added onto the substrate to form nanostructures; the atoms, and then the resulting crystal planes are stacking onto each other, ensuring the synthesis of the nanostructures (Pelgrift and Friedman 2013). 


\section{General mechanisms of the antimicrobial activity of NPs}

The antimicrobial features of nanoparticles could be used to complement current antimicrobial agents that fail to combat pathogens, including multidrug-resistant and biofilm-forming microorganisms (Baek and An 2011; Pornpattananangkul et al., 2011). Various chemical composition characteristics, such as size, coating, particle nature, solvent, nanomaterial ratio as well as oxygen concentration, $\mathrm{pH}$ and temperature are significantly influencing their antimicrobial activity (Ashkarran et al., 2012).

The modes of antimicrobial activity summarized in Fig. 1 are dependent on the type of the microbial target (i.e., cell wall structure, metabolic pathways) and the physiological state of the microbial cells (i.e., planktonic, biofilm) (Nath and Banerjee 2013; Dizaj et al. 2014).

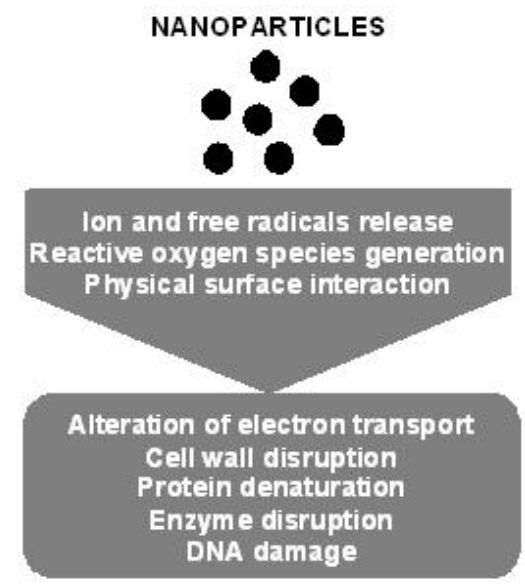

Fig. 1. The main reported mechanisms of toxicity of metal NPs on bacterial cells.

Structural and functional alteration of cytoplasmic membrane is a nonspecific mechanism of action similar to that of polymixins (Leroueil et al., 2007). The physical contact between NPs and microbial membrane causes the formation of "pore" like structures that affect the cellular permeability. In more severe cases a hole in the bilayer membrane is produced which promotes the complete loss of plasma membrane (Niskanen et al., 2010).

Release of toxic ions. Experimental data showed that metallic ions $\left(\mathrm{Zn}^{2+}, \mathrm{Ag}^{+}\right)$bind to different proteins from the bacterial cytoplasmic membrane, altering its permeability. Silver NPs, at concentrations of $10^{-9} \mathrm{~mol} / \mathrm{l}$, release silver ions which could cause damages at the level of cytoplasmic membrane, interfere with microbial metabolic pathways and alter the DNA replication. This mode of action of $\mathrm{Ag}^{+}$ions has been demonstrated for Gram negative bacteria. The $\mathrm{Zn}^{2+}$ ions also interact with membrane proteins altering the cell permeability (Allaker 2010).

Disruption of electron transport, protein oxidation and membrane collapse. Metallic NPs are positively charged, this feature being essential for their antimicrobial activity. It has been suggested that ions similar to silver can affect membrane-bound respiratory enzymes and inactivate ions efflux pumps (Spacciapoli et al., 2001).

Generation of ROS molecules. Direct contact of NPs with microbial cells promotes oxidation of respiratory enzymes, production of ROS with damaging effects on DNA and cell physiology (Bronshtein et al., 2006). Triplet oxygen (or $\left.{ }^{3} \mathrm{O}_{2}\right)$ and singlet oxygen $\left({ }^{1} \mathrm{O}_{2}\right)$ cause deleterious effects on microorganisms, through peroxidation of cellular constituents, like proteins and lipids. The release of free hydroxyl radicals is the basis of hydrogen peroxide action and this reaction is necessary for the oxidation of DNA, proteins and membrane lipids (Seil and Webster 2012). Production of ROS molecules causes the loss of membranes integrity and inhibition of microbial adherence. Many microorganisms defend themselves against ROS by producing anti-oxidant enzymes, such as SoxRS and the OxyR (Dizaj et al., 2014).

\section{Antimicrobial features of different types of inorganic and organic NPs}

Due to their unique proprieties and high biocompatibility, nanomaterials are intensively investigated for a variety of biomedical applications including the development of novel antimicrobials.

\section{Metal-based nanoparticles}

\section{a. Silver NPs (Ag NPs)}

Silver has been extensively used throughout the human recorded history for a variety of medical purposes such as wound dressing component, disinfection of clinical devices etc. Ag NPs, similarly to other non-antibiotic remedies turned into nearly deserted when penicillin and later on other antibiotics have been discovered (Chopra 2007). Several in vitro and in vivo studies have demonstrated the large antimicrobial spectrum of silver NPs (De Simone et al., 2014). It has been demonstrated that Ag NPs could also enhance the efficiency of conventional antibiotics against Gram positive and Gram negative strains (Morones-Ramirez et al., 2013).

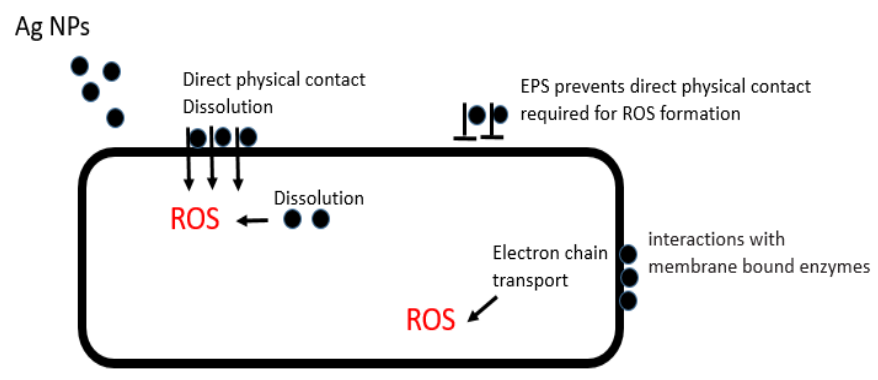

Fig. 2. Illustration of cellular mechanisms of ROS generation by Ag NPs in bacterial cell.

Ag NPs alter the cell membrane permeability by producing "holes" within the cell wall. The respiratory chain is also affected through the modification of protein 
structure due to its affinity for sulphur and nitrogen groups (Choi et al., 2008). An additional mechanism is generation of ROS molecules (Luther et al., 2011; von Moos and Slaveykova 2014) (Fig. 2). The antimicrobial activity of Ag NPs has been proved to be size-dependent (Panáček et al., 2006).

\section{Metal-oxide nanoparticles}

\section{a. Zinc oxide NPs (ZnO NPs)}

$\mathrm{ZnO}$ NPs have been shown to have excellent antimicrobial efficiency against different microbes depending on concentration and particle size (Malka et al., 2013). For example, $\mathrm{ZnO}$ NPs have been demonstrated to inhibit the growth of Gram positive (methicillin resistant Staphylococcus aureus, Bacillus subtilis) and Gram negative bacteria (Klebsiella pneumoniae, Escherichia coli) (Silver and Ji 1994; Huh and Kwon 2011; Adams et al., 2014). Also, it was found that $\mathrm{ZnO}$ NPs exhibit antimicrobial activity against food borne pathogens, such as Salmonella typhimurium and enterotoxigenic and enterohemorrhagic E. coli (Hamouda and Baker, 2000). The mechanisms of the antimicrobial action of $\mathrm{ZnO}$ NPs include: the attachment to cytoplasmic membrane and subsequently, potential disruption and loss of membrane integrity and the promotion of ROS production (Pan et al., 2010). Previous studies have shown that $\mathrm{Zn}$ increases the percentage of ciprofloxacin release in a controlled manner. The antimicrobial properties of $\mathrm{ZnO}$ NPs support their use for fabrication of materials designed for biomedical applications, such as dressings, orthopedic prostheses etc. (Aydin Sevinç and Hanley, 2010).

\section{b. Titanium dioxide $\left(\mathrm{TiO}_{2} \mathrm{NPs}\right)$}

Titanium is found in nature, in particular in the form of titanium dioxide $\left(\mathrm{TiO}_{2}\right)$. It is a hard and brittle metal, but lighter than other metals with similar mechanical and thermal properties. The titanium properties determine their use in different scientific fields, including medicine. The antimicrobial activity of $\mathrm{TiO}_{2}$ is due to the generation of hydroxyl radicals $\left(\mathrm{OH}^{-}\right)$when irradiated with UV light at wavelengths of less than $385 \mathrm{~nm}$ (Wei et al., 1994). The nanostructured $\mathrm{TiO}_{2}$ can be used for the improvement of antimicrobial activity of surfaces used in the food industry correlated with the decrease of the disinfection time (Chorianopoulos et al., 2011). The small diameter has been shown to be correlated with a high antibacterial activity. For instance, in a study using a variety of $\mathrm{TiO}_{2}$ nanoparticles with a diameter between 12 and $707 \mathrm{~nm}$ and with zeta potential values between 50 and $44 \mathrm{mV}$, in concentrations of 10,100 and $500 \mathrm{pg} / \mathrm{ml}$, it was observed that the greatest antimicrobial activity was obtained for NPs with tiny diameters and positive zeta potential, whereas NPs with large diameters or with a negative zeta potential, were ineffective against microorganisms (Ng et al., 2013).

\section{c. Superparamagnetic iron oxide nanoparticles (SPIONs)}

SPIONs are largely used in biomedical applications including such as targeted drug delivery and magnetic resonance imaging. Studies demonstrated that SPIONs with different surface coatings (e.g., gold and silver) exhibit superior antibacterial proprieties against pathogenic biofilm forming bacteria by comparison with antibiotics or metal salts alone (Subbiahdoss et al., 2012; Taylor et al., 2012). Carboxyl-grafted SPIONs showed a stronger antibacterial effect against Staphyloccocus sp. biofilm than gentamicin. Additionally, experimental studies showed that by using external magnetic field, carboxyl-grafted SPIONs exhibited a significantly ability to destroy bacteria in an established biofilm. Thus it represents an effective strategy for the control of medical device associated infections caused by antibiotic-resistant and biofilm producer pathogens.

\section{d. Carbon NPs (C NPs)}

Carbon NPs in particular fullerene, carbon nanotubes, graphene and diamond-like carbon structures have been employed for the development of new antimicrobial agents due to the high surface to volume ratio and their unique chemical and physical properties (Varghese et al., 2013). Investigations have revealed that as the size of carbon particles decreases right down to the nanoscale range, their antimicrobial activity will increase due to their larger surface area consistent with unit volume and high percentage of atoms in the surface and near-surface layers. C NPs have been found to be effective against bacterial strains such as Pseudomonas aeruginosa and $S$. aureus (Varghese et al., 2013). Also, previous studies demonstrated the antimicrobial properties of singlewalled carbon nanotubes (SWCNT) and multi-walled carbon nanotubes (MWCNT) against different pathogenic bacteria (E. coli, S. epidermidis, B. subtilis, S. aureus) (Kang et al., 2006). Additional studies have shown that $C$ NPs exposure increases the expression of stress-related genes, membrane disruption and cytotoxicity (Musee et al., 2011).

\section{Organic nanomaterials}

Nanotechnology employs different types of polymers, either natural (e.g., chitosan, collagen) or synthetic polymers [e.g., polyvinyl chloride (PVC), ethylene vinyl acetate (EVA) and polyvinyl acetate (PVA)] (Beyth et al., 2015).

\section{a. Chitosan (Ch NPs)}

Chitosan results from the N-deacetylation of chitin found within the shells of crustaceans. It is formed of glucosamine and $\mathrm{N}$-acetyl glucosamine residues linked by $\beta$ 1-4 glucosidic bonds and is one of the most broadly studied natural polymers for nano-drug delivery. The deacetylation of chitin is concentration and temperature dependent with optimal yields achieved at temperatures between 80 and $120{ }^{\circ} \mathrm{C}$ using alkaline solution (Younes and Rinaudo, 2015). The wide applications of chitosan 
are based on biocompatibility, nontoxic nature, antibacterial features, low immunogenicity, and the potential to behave as an absorption enhancer. Ch NPs exhibit also a pronounced antibacterial, antiviral, and antifungal effect (Chung et al., 2003; Tavaria et al., 2013), which is $\mathrm{pH}$ and solvent dependent. Previously, chitosan-hydroxycinnamic acid conjugates with high bactericidal activity have been developed (Rabea et al., 2003). On the other side, $\mathrm{Ch}$ has been demonstrated to inhibit the antimicrobial effect of a metallic nanomaterials, such as ZnNPs (Huh and Kwon 2011). The antimicrobial mode of action Ch NPs is not entirely understood (Ibrahim et al., 2014). Previous studies have indicated disruption of cell membrane functions (proteins inactivation, interfering with respiratory chain, drug efflux system and transport), resulting in membrane lysis and cell death (Bratlie et al., 2012).

\section{b. Ethylene-vinyl acetate (EVA)}

Ethylene-vinyl acetate and related polymers are used as substrates for drug release, for instance, intravitreal devices employed for eye infection treatment, antibioticreleasing coatings for urethral catheters (Thurman et al., 2013). Nanocomposites with antimicrobial agents are of great interest nowadays. For instance, Ag NPs coupled with $\mathrm{TiO}_{2}$ NPs dispersed in LDPE/EVA resulted in excellent antimicrobial properties (Da Olyveira et al., 2011).

\section{c. Polyvinyl chloride (PVC)}

Polyvinyl chloride is one of the most extensively used polymers in medical applications due to its excellent chemical resistance, transparency, resistance to burning and low cost (Baker et al., 2012). According to the Vinyl Institute (Alexandria, Virginia, USA), 25\% of all medical products contain plastics made of polyvinyl chloride, synthesized by polymerization of the vinyl chloride monomer (VCM) (Munoz-Bonilla and Fernandez-Garcia, 2012). Flexible grades of PVC are used in medical devices such as IV bags, tubes, and catheters, which are in prolonged contact with biological fluids or their synthetic substitutes. So, it is important to prevent microbial adherence and proliferation on these materials. A medical-grade polyvinyl chloride with antimicrobial properties is an alternative to reduce microbial infections caused by medical devices. Several studies have reported the preparation of antimicrobial PVC, most of them being obtained through incorporation of an antimicrobial agent into the polymer matrix (Chanda and Roy, 2006). Metallic and metal oxide NPs, such as those formed of $\mathrm{Cu}, \mathrm{Ag}, \mathrm{ZnO}, \mathrm{TiO}_{2}$ have been used to prepare polyvinyl chloride nanocomposite with bactericidal properties.

\section{d. Polyvinyl alcohol (PVA)}

Polyvinyl alcohol is a synthetic, biodegradable, biocompatible, water-soluble polymer that with many medical applications, i.e. wound dressings, artificial skin, coatings, transdermal patches, cardiovascular devices, and drug delivery structures. The physical characteristics of PVA are dependent on treatment technique of poly (vinyl acetate) (Galya et al., 2008). PVA is a linear polymer that can be cross-linked into hydrogels for drug delivery application. Conventional methods for crosslinking PVA use irradiation or bifunctional groupcontaining chemical agents like glutaraldehyde. The cross-linking agents and hydrogel preparation can influence the drugs loading. It is mainly true for protein and peptide drugs incorporated in the hydrogel. Also, the chemical method of preparation may additionally introduce residual substances in the hydrogels formed. Previous studies demonstrated that the $\mathrm{PVA} / \mathrm{AgNO}_{3}$ nanocomposite is a suitable material for preparation of antimicrobial nanofibers, being active against $S$. aureus and K. pneumoniae bacterial strains (Galya et al., 2008).

\section{Nanotechnology-based anti-biofilm strategies}

Taking into account the high tolerance to antimicrobials and deleterious effects of biofilms, in medical field, but also in different man-made environments, various nanotechnology- based strategies to fight against biofilms are being currently developed.

Medical devices surface modification is one of the most common anti-biofilm strategies. The main approaches employed are physico-chemical modification and incorporation of antimicrobial substances (Shunmugaperumal, 2010).

Physical techniques, such as plasma method, ion-beam change, and photo-grafting, are currently used to modify the material hydrophobicity in order to decrease adsorption of microbial cell or increase the attraction or retention of antimicrobial agents at the surface or allow the connection of a drug delivery mechanism (Pavithra and Doble, 2008). The surface photo-grafting is a technique used to manipulate the chemical structure of biomaterials in order to enhance their hemocompatibility and interfere with the microbial cells adhesion (Chen and Wen 2011).

It has been shown that catheters modified with $\mathrm{MgF} 2$ NPs can restrict the biofilms development of pathogens like E. coli and $S$. aureus (Lellouche et al., 2012). The surfaces coated with ZnO NPs can promote ROS production interfering with $E$. coli and $S$. aureus biofilms development (Applerot et al., 2012).

In case of the nitric oxide-releasing NPs, the rapid diffusion properties of nitric oxide result in enhanced penetration of biofilms matrix and improved antimicrobial activity against biofilm-embedded microorganisms. Nitric oxide exhibited antimicrobial activity against Gram negative bacteria, such as $P$. aeruginosa and E. coli (Hetrick et al., 2009). The Au or Ag surface coated SPIONs demonstrated a strong inhibitory activity against $P$. aeruginosa biofilms enhanced by the thermal effect. Additionally, SPIONs do not only create heat in the specific area where the magnetic field is applied but also, they may be used to 
release chemicals such as antimicrobial agents (Park et al., 2011).

\section{Conclusions}

Nanotechnology significantly contributes to the spectacular progress in the advancement of biologically effective materials and in the same time to the achievement of important knowledge of materials at the atomic and molecular scale. Innovative materials with novel and unique antimicrobial activity are continuously developed and considerable progress has been achieved within a short period of time, opening promising research directions for the development of efficient strategies for combating planktonic and biofilm embedded microorganisms.

\section{Acknowledgments}

This work was supported by a grant of the Romanian National Authority for Scientific Research and Innovation, CCCDIUEFISCDI, project number 234PED/2017.

(C)The Author(s) 2018

Open Access This article is distributed under the terms of the Creative Commons Attribution 4.0 International License (http://creativecommons.org/licenses/by/4.0/) which permits unrestricted use, distribution, and reproduction in any medium, provided you give appropriate credit to the original author(s) and the source, provide a link to the Creative Commons license, and indicate if changes were made.

\section{References}

Adams C.P., Walker K.A., Obare S.O., Docherty K.M. 2014. Size-dependent antimicrobial effects of novel palladium nanoparticles. PLoS One. 9, p.e85981. doi.org/10.1371/journal.pone.0085981.

Allaker R.P. 2010. The use of nanoparticles to control oral biofilm formation. J. Dent. Res. 89, 1175-1186.

Applerot G., Lellouche J., Perkas N., Nitzan Y., Gedanken A., Banin E. 2012. ZnO nanoparticle-coated surfaces inhibit bacterial biofilm formation and increase antibiotic susceptibility. RSC Adv. 2, 23142321.

Ashkarran A.A., Ghavami M., Aghaverdi H., Stroeve P. and Mahmoudi M. 2012. Bacterial effects and protein corona evaluations: crucial ignored factors in the prediction of bio-efficacy of various forms of silver nanoparticles. Chem. Res. Toxicol. 25, 1231-1242.

Aydin Sevinç B., Hanley L. 2010. Antibacterial activity of dental composites containing zinc oxide nanoparticles. J. Biomed. Mater. Res. B. Appl. Biomater. 94, 22-31.

Baek Y.W., An Y.J. 2011. Microbial toxicity of metal oxide nanoparticles $\left(\mathrm{CuO}, \mathrm{NiO}, \mathrm{ZnO}\right.$, and $\left.\mathrm{Sb}_{2} \mathrm{O}_{3}\right)$ to
Escherichia coli, Bacillus subtilis, and Streptococcus aureus. Sci. Total Environ. 409, 1603-1608.

Baker M.I., Walsh S.P., Schwartz Z., Boyan B.D. 2012. A review of polyvinyl alcohol and its uses in cartilage and orthopedic applications. J. Biomed. Mater. Res. B. Appl. Biomater. 100, 1451-1457.

Beyth N., Houri-Haddad Y., Domb A., Khan W., Hazan R. 2015. Alternative antimicrobial approach: nanoantimicrobial materials. J. Evid. Based Complementary Altern. Med. 246012. doi.org/10.1155/2015/246012.

Bhatia S. 2016. Nanoparticles Types, Classification, Characterization, Fabrication Methods and Drug Delivery Applications. In: Natural Polymer Drug Delivery Systems. Springer: Cham, 33-93.

Bratlie K.M., York R.L., Invernale M.A., Langer R. Anderson D.G. 2012. Materials for diabetes therapeutics. Adv Healthc. Mater. 1, 267-284.

Bronshtein I., Aulova S., Juzeniene A., Lanl V., Ma L.W., Smith K.M., Malik Z., Moan J., Ehrenberg B., 2006. In vitro and in vivo photosensitization by protoporphyrins possessing different lipophilicities and vertical localization in the membrane. J. Photochem. Photobiol. 82, 1319-1325.

Buzea C., Pacheco I.I., Robbie K. 2007. Nanomaterials and nanoparticles: Sources and toxicity. Biointerphases. 2, MR17-MR71. doi.org/10.1116/ 1.2815690.

Chanda M. and Roy S.K. 2006. Plastics technology handbook (ed 4.). Florida, USA: CRC Press.

Chen L., Wen Y.M. 2011. The role of bacterial biofilm in persistent infections and control strategies. Int J. Oral. Sci. 3, 66-73.

Choi O., Deng K.K., Kim N.J., Ross L., Surampalli R.Y., $\mathrm{Hu}$ Z. 2008. The inhibitory effects of silver nanoparticles, silver ions, and silver chloride colloids on microbial growth. Water Res. 42, 3066-3074.

Chopra I. 2007. The increasing use of silver-based products as antimicrobial agents: a useful development or a cause for concern?. J. Antimicrob. Chemother. 59, 587-590.

Chorianopoulos N.G., Tsoukleris D.S., Panagou E.Z., Falaras P., Nychas G.J. 2011. Use of titanium dioxide $\left(\mathrm{TiO}_{2}\right)$ photocatalysts as alternative means for Listeria monocytogenes biofilm disinfection in food processing. Food Microbiol. 28, 164-170.

Christian P., Von der Kammer F., Baalousha M., Hofmann T. 2008. Nanoparticles: structure, properties, preparation and behavior in environmental media. Ecotoxicology. 17, 326-343.

Chung Y.C., Wang H.L., Chen Y.M., Li S.L. 2003. Effect of abiotic factors on the antibacterial activity of chitosan against waterborne pathogens. Bioresour. Technol. 88, 179-184.

Da Olyveira G.M., Costa L.M.M., da Carvalho A.J.F., Basmaji P. and Pessan L.A. 2011. Novel LDPE/EVA Nanocomposites with Silver/Titanium Dioxide Particles for Biomedical Applications. JME. B. 1(4B), 516-522. 
Daniel M.C., Astruc D. 2004. Gold nanoparticles: assembly, supramolecular chemistry, quantum-sizerelated properties, and applications toward biology, catalysis, and nanotechnology. Chem. Rev. 104, 293346.

De Simone S., Gallo A.L., Paladini F., Sannino, A., Pollini, M. 2014. Development of silver nano-coatings on silk sutures as a novel approach against surgical infections. J. Mater. Sci. Mater Med. 25, 2205-2214.

Dizaj S.M., Lotfipour F., Barzegar-Jalali M., Zarrintan M.H., Adibkia K. 2014. Antimicrobial activity of the metals and metal oxide nanoparticles. Mater. Sci. Eng. C Mater. Biol. Appl. 44, 278-284.

Galya T., Sedlařík V., Kuřitka I., Novotný R., Sedlaříková J., Sáha, P. 2008. Antibacterial poly (vinyl alcohol) film containing silver nanoparticles: preparation and characterization. J. Appl. Polym. Sci. 110, 3178-3185.

Gupta A., Landis R.F. Rotello V.M. 2016. Nanoparticlebased antimicrobials: Surface functionality is critical. F1000Res. 5, F1000 Faculty Rev-364. doi: 10.12688/f1000research.7595.1F1000Research.

Hamouda T., Baker J.R. 2000. Antimicrobial mechanism of action of surfactant lipid preparations in enteric Gram-negative bacilli. J. Appl. Microbiol. 89, 397-403.

Hetrick E.M., Shin J.H., Paul H.S., Schoenfisch M.H. 2009. Anti-biofilm efficacy of nitric oxide-releasing silica nanoparticles. Biomaterials 30, 2782-2789.

Huh A.J., Kwon Y.J. 2011. "Nanoantibiotics": a new paradigm for treating infectious diseases using nanomaterials in the antibiotics resistant era. J. Control. Release. 156, 128-145.

Ibrahim M., Tao Z., Hussain A., Chunlan Y., Ilyas M., Waheed A., Yuan F., Li B., Xie G.L. 2014. Deciphering the role of Burkholderia cenocepacia membrane proteins in antimicrobial properties of chitosan. Arch. Microbiol. 196, 9-16.

Jiang Z., Le N.D., Gupta A., Rotello V.M. 2015. Cell surface-based sensing with metallic nanoparticles. Chem. Soc. Rev. 44, 4264-4274.

Jores K., Mehnert W., Drechsler M., Bunjes H., Johann C., Mäder K. 2004. Investigations on the structure of solid lipid nanoparticles (SLN) and oil-loaded solid lipid nanoparticles by photon correlation spectroscopy, field-flow fractionation and transmission electron microscopy. J. Control. Release. 95, 217-227.

Kang I., Schulz M.J., Kim J.H., Shanov V., Shi D. 2006. A carbon nanotube strain sensor for structural health monitoring. Smart Mater. Struct. 15, 737-748.

Lellouche J., Friedman A., Lahmi R., Gedanken A. Banin E. 2012. Anti-biofilm surface functionalization of catheters by magnesium fluoride nanoparticles. Int. J. Nanomedicine. 7, 1175-88.

Leroueil P.R., Hong S., Mecke A., Baker Jr J.R., Orr B.G., Banaszak Holl M.M. 2007. Nanoparticle interaction with biological membranes: does nanotechnology present a Janus face?. Acc. Chem. Res. 40, 335-342.
Luther E.M., Koehler Y., Diendorf J., Epple M., Dringen R. 2011. Accumulation of silver nanoparticles by cultured primary brain astrocytes. Nanotechnology. 22, 375101. doi: 10.1088/0957-4484/22/37/375101.

Malka E., Perelshtein I., Lipovsky A., Shalom Y., Naparstek L., Perkas N., Patick T., Lubart R., Nitzan Y., Banin E., Gedanken A. 2013. Eradication of Multi-Drug Resistant Bacteria by a Novel Zn-doped CuO Nanocomposite. Small. 9, 4069-4076.

Miller K.P., Wang L., Benicewicz B.C., Decho, A.W. 2015. Inorganic nanoparticles engineered to attack bacteria. Chem. Soc. Rev. 44, 7787-7807.

Morones-Ramirez J.R., Winkler J.A., Spina C.S., Collins J.J. 2013. Silver enhances antibiotic activity against Gram (-) bacteria. Sci. Transl. Med. 5, 190ra81190ra81. doi: 10.1126/scitranslmed.3006276.

Muñoz-Bonilla A., Fernández-García, M. 2012. Polymeric materials with antimicrobial activity. Prog. Polym. Sci. 37, 281-339.

Musee N., Thwala M., Nota N. 2011. The antibacterial effects of engineered nanomaterials: implications for wastewater treatment plants. J. Environ. Monit. 13, 1164-83.

Nath D., Banerjee P. 2013. Green nanotechnology-A new hope for medical biology. Environ. Toxicol. Pharmacol. 36, 997-1014.

Ng A.M.C., Chan C.M.N., Guo M.Y., Leung Y.H., Djurišić A.B., Hu X., Chan W.K., Leung F.C.C. Tong S.Y. 2013. Antibacterial and photocatalytic activity of $\mathrm{TiO}_{2}$ and $\mathrm{ZnO}$ nanomaterials in phosphate buffer and saline solution. Appl. Microbiol. Biotechnol. 97, 55655573.

Niskanen J., Shan J., Tenhu H., Jiang H., Kauppinen E., Barranco V., Picó F., Yliniemi K., Kontturi K. 2010. Synthesis of copolymer-stabilized silver nanoparticles for coating materials. Colloid Polym. Sci. 288, 543-553.

Pan X., Redding J.E., Wiley P.A., Wen L., McConnell J.S., Zhang B. 2010. Mutagenicity evaluation of metal oxide nanoparticles by the bacterial reverse mutation assay. Chemosphere. 79, 113-116.

Panáček A., Kvítek L., Prucek R., Kolář M., Večeřová R., Pizúrová N., Sharma V.K., Nevěčná T.J., Zbořil, R. 2006. Silver colloid nanoparticles: synthesis, characterization, and their antibacterial activity. $J$. Phys. Chem. B. 110, 16248-16253.

Park H., Park H.J., Kim J.A., Lee S.H., Kim J.H., Yoon J., Park T.H. 2011. Inactivation of Pseudomonas aeruginosa PA01 biofilms by hyperthermia using superparamagnetic nanoparticles. J. Microbiol. Methods. 84, 41-45.

Pavithra D., Doble M. 2008. Biofilm formation, bacterial adhesion and host response on polymeric implantsissues and prevention. Biomed. Mater. 3, 034003. doi: 10.1088/1748-6041/3/3/034003.

Pelgrift R.Y., Friedman A.J. 2013. Nanotechnology as a therapeutic tool to combat microbial resistance. Adv. Drug Deliv. Rev. 65, 1803-1815. 
Pornpattananangkul D., Zhang L., Olson S., Aryal S., Obonyo M., Vecchio K., Huang, C.M., Zhang, L. 2011. Bacterial toxin-triggered drug release from gold nanoparticle-stabilized liposomes for the treatment of bacterial infection. J. Am. Chem. Soc. 133, 4132-4139.

Rabea E.I., Badawy M.E.T., Stevens C.V., Smagghe G., Steurbaut, W. 2003. Chitosan as antimicrobial agent: applications and mode of action. Biomacromolecules. 4, 1457-1465.

Seil J.T., Webster T.J. 2012. Antimicrobial applications of nanotechnology: methods and literature. Int. $J$. Nanomedicine 7, 2767-2781.

Shunmugaperumal T. 2010. Microbial colonization of medical devices and novel preventive strategies. Recent. Pat. Drug. Deliv. 4, 153-173.

Silver S., Ji G. 1994. Newer systems for bacterial resistances to toxic heavy metals. Environ. Health Perspect. 102, 107-113.

Spacciapoli P., Buxton D., Rothstein D., Friden P. 2001. Antimicrobial activity of silver nitrate against periodontal pathogens. J. Periodontal. Res. 36, 108113.

Subbiahdoss G., Sharifi, S., Grijpma D.W., Laurent S., van der Mei H.C., Mahmoudi, M., Busscher, H.J. 2012. Magnetic targeting of surface-modified superparamagnetic iron oxide nanoparticles yields antibacterial efficacy against biofilms of gentamicinresistant staphylococci. Acta Biomater. 8, 2047-2055.

Tavaria F.K., Costa E.M., Gens E.J., Malcata F.X. Pintado M.E. 2013. Influence of abiotic factors on the antimicrobial activity of chitosan. J. Dermatol. 40, 1014-1019.

Taylor E.N., Kummer, K.M., Durmus N.G., Leuba K., Tarquinio K.M., Webster T.J. 2012. Superparamagnetic iron oxide nanoparticles (SPION) for the treatment of antibiotic-resistant biofilms. Small. 8, 3016-3027.

Thurman A.R., Clark M.R., Hurlburt J.A., Doncel G.F., 2013. Intravaginal rings as delivery systems for microbicides and multipurpose prevention technologies. Int. J. Womens Health. 5, 695-708.

Varghese S., Kuriakose S., Jose S. 2013. Antimicrobial activity of carbon nanoparticles isolated from natural sources against pathogenic Gram (-) and Gram (+) bacteria. J. Nanosci. 2013. doi.org/10.1155/ 2013/457865.

von Moos N., Slaveykova V.I. 2014. Oxidative stress induced by inorganic nanoparticles in bacteria and aquatic microalgae - state of the art and knowledge gaps. Nanotoxicology. 8, 605-630.

Wei C., Lin W.Y., Zainal Z., Williams N.E., Zhu K., Kruzic A.P., Smith R.L., Rajeshwar K. 1994. Bactericidal activity of $\mathrm{TiO}_{2}$ photocatalyst in aqueous media: toward a solar-assisted water disinfection system. Environ. Sci. Technol. 28, 934-938.

Younes I., Rinaudo, M. 2015. Chitin and chitosan preparation from marine sources. Structure, properties and applications. Mar. Drugs. 13, 133-1174. 